\title{
Results of investigation into statin side effects due by end of year
}

\author{
Nigel Hawkes
}

London

The Cholesterol Treatment Trials Collaboration plans to produce tabulated results of all the side effects recorded in 30 randomised controlled trials of statins by the end of this year, the Oxford University expert Rory Collins told a briefing at the Science Media Centre in London this week.

But he did not expect the results to "materially alter the evidence," which he said strongly favoured statins. "It may reassure some people," he said. "We thought it was necessary to get the data out there."

The task of searching large volumes of patient level data would take several people the equivalent of a year of work, he estimated. "The cost is not trivial, but the public health costs of not taking a drug we know is very effective and very safe are bigger," he said.

He added that the plan to conduct the study was not new and that he had been surprised by comments attributed to Fiona Godlee, editor in chief of The BMJ, in the Sunday Express, that seemed to imply the study was new to her. He had written a letter to her last autumn describing the study, which he had expected would be published in The BMJ. The study had also been described in submissions to the panel chaired by Iona
Heath, who adjudicated the disagreement between Collins and The $B M J$ over the possible side effects of statins.

He was asked why he had not publicised more widely the intention to carry out the study, because doing so might have reassured the public that all possible was being done to ensure that the drugs taken by millions were safe. He insisted that he had been entirely open about the study and that his letter to The $B M J$ and to the Heath panel should have been sufficient.

He said that it would not be clear until the data were gathered what would be the best way to publish them but suggested that in the first instance they could be published as a simple tabulation. "We will bring together all the adverse events that were recorded in the trials and see if there are any small effects," he said. "It is going to be very fine detail. In terms of materially altering the known benefits and risks, it won't do that."

For more on The BMJ and the statins data issue see thebmj.com/campaign/statins-open-data.

Cite this as: BMJ 2015;350:h957

๑ BMJ Publishing Group Ltd 2015 